\title{
Red Blood Cell Alloimmunization in Pediatric Sickle Cell Disease Population of Puerto Rico: An Observational Study
}

\author{
Raisa I. Balbuena-Merle (), M.D. ${ }^{1,4}$, Cruz M. Nazario-Delgado (i), Ph.D. ${ }^{2}$, Rosa V. Rosario-Rosado (), Dr.PH. ${ }^{2}$, \\ Dalia Millán-Tapia (i), M.T. ${ }^{3}$, and Consuelo Climent-Peris (), M.D. ${ }^{1,3}$ \\ ${ }^{1}$ Department of Pathology and Laboratory Medicine, School of Medicine, University of Puerto Rico, San Juan, Puerto Rico; ${ }^{2}$ Graduate School of Public \\ Health, School of Medicine, University of Puerto Rico, San Juan, Puerto Rico; ${ }^{3}$ Medical Services Administration of Puerto Rico, Clinical Laboratory \\ Transfusion Service, San Juan, Puerto Rico; ${ }^{4}$ Yale University, Department of Laboratory Medicine, New Haven, CT, USA
}

\section{Dear Editor,}

We read with interest the manuscript by Kim, et al. [1] regarding high rates of red blood cell (RBC) alloimmunization in patients with myelodysplastic syndrome (MDS) and liver cirrhosis. Another population with an increased risk of RBC alloimmunization includes patients with sickle cell disease (SCD), with prevalence rates as high as 40-50\% [2]. As in MDS, the management of SCD may require acute or chronic RBC transfusions, increasing the exposure to non-self RBC antigens that could result in the formation of alloantibodies [3].

We hypothesized that the RBC alloimmunization prevalence in patients with SCD in Puerto Rico (PR) would be lower than that of other described SCD patients, owing in part to genetic homogeneity between blood donors and transfusion recipients $[4,5]$, as well as due to an initiative of our transfusion service to provide phenotypically matched RBCs when feasible. To our knowledge, no prior studies have been published on RBC alloimmunization rates in SCD patients living in PR. This study was approved by the Institutional Review Board of The Medical Sciences Campus, University of PR, San Juan, PR (approval number: B0870116) which waived informed consent.
We reviewed retrospectively the medical records of all children with SCD, diagnosed using $\mathrm{Hb}$ electrophoresis and transfused at the PR Medical Center, Rio Piedras, PR, within a nine-year period (July 2005 to December 2014). Inclusion criteria were age $<18$ years, a complete RBC phenotype on file, a complete transfusion history, follow-up antibody screening, and no transfusions prior to 2005 (the date the electronic medical record system was implemented). Each RBC transfusion was categorized into three groups according to the degree of serologic antigen phenotype matching: ABO/D, matched for Rh (C,C, E,e) and $\mathrm{K}$ ("limited phenotype matched"), or more extensively matched for Rh and $\mathrm{K}$ in addition to Fy, Jk, and MNS ("extended phenotype matched"). A total of 52 children with SCD (SS, SB+, SBO, and SC) met this study's inclusion criteria. Their median age was eight yrs (interquartile range, IQR: 16 years), and 35\% were females. Overall, the patients received 302 RBC units (median: 3 units, IQR: 36 units). Over the nine-year study period, by necessity, 22 of the patients received blood with differing degrees of antigenic matching. Of these 22 patients, 13 received both limited and extended phenotype matched units. Antibody screening was completed in a tube and/or gel prior to each transfusion,
Received: May 31, 2019

Revision received: July 5, 2019

Accepted: October 1, 2019

Corresponding author: Raisa I. Balbuena-Merle, M.D.

Department of Laboratory Medicine, Yale University, 330 Cedar Street, Clinic Building 441, New Haven, CT 06520-8035, USA

Tel: +1-203-688-2286, Fax: +1-203-688-7340

E-mail: raisa.balbuena-merle@yale.edu

\section{(c) (1) $(9$}

(C) Korean Society for Laboratory Medicine

This is an Open Access article distributed under the terms of the Creative Commons Attribution Non-Commercial License (http://creativecommons.org/licenses/by-nc/4.0) which permits unrestricted non-commercial use, distribution, and reproduction in any medium, provided the original work is properly cited. 
and any newly detected antibody was attributed to the previous transfusion.

Eight (15.4\%) patients developed RBC alloantibodies at some points over the study period. RBC alloantibodies were more common in males (17.6\%) than in females (11.1\%). The transfusion burden of the eight patients with RBC alloantibodies ("responders") was 50 units (median: 1.5 units, IQR: 6.5 units), and that of the non-responders was 252 units (median: 3 units, IQR: 4.5 units). Nine new RBC alloantibody formation events were observed following the 302 transfusion events, for an overall alloimmunization prevalence of 3\% (9/302). These antibodies had specificities against $\mathrm{M}(\mathrm{N}=4$; all lgG class), $\mathrm{E}(\mathrm{N}=1), \mathrm{K}(\mathrm{N}=1)$, Fy $^{\mathrm{a}}(\mathrm{N}=2)$, and $\mathrm{Jk}^{\mathrm{a}}(\mathrm{N}=1)$ (Fig. 1).

One patient received a non-matched unit and developed anti$\mathrm{K}$ antibodies; two years later, an anti-Jk ${ }^{\mathrm{a}}$ antibody was identified following a non-matched transfusion. The patient received only extended phenotype-matched RBC transfusions between these alloimmunization events. A total of 26/302 (9\%) of the transfused RBC units were matched for only ABO/RhD, 124/302 (41\%) were "limited phenotype matched," and 152/302 (50\%) were "extended phenotype matched."

We calculated the prevalence of alloimmunization by transfusion events during this nine-year period. Of the nine antibodies formed, four occurred following ABO/D matched RBC transfu- sions (4/26 transfusion events $=15.4 \%$ ), five occurred following "limited phenotype matched" RBC transfusions (5/124 transfusion events $=4 \%$ ), and none occurred following "extended phenotype matched" RBC transfusions (0/152 transfusion events = $0 \%$; Fig. 1). In addition, the distribution of RBC antigens in the SCD population in PR did not completely correlate with either Caucasians or Blacks [6]; rather, it was generally positioned between the prevalence of both groups (Table 1 ).

The low percentage of antibodies in the Rh family could reflect a combination of decreased exposure to non-self-antigens as a result of our phenotypic matching, in addition to the lower Rh genetic diversity in this population compared with individuals living in the mainland US [7, 8]. Future genotyping studies on the RBC donors and the SCD patient population in PR may be informative.

In summary, the PR pediatric SCD population demonstrated a 15.4\% RBC alloimmunization prevalence, which is lower than the overall prevalence reported in other SCD populations and closer to the prevalence observed in more homogeneous populations [4, 5]. The observed specificities of all antibodies formed, in combination with the fact that $0 \%$ of our patients developed new alloantibodies after receiving "extended phenotype matched" RBCs, support the phenotypic matching strategy proposed in this journal by Kim, et al. [1].
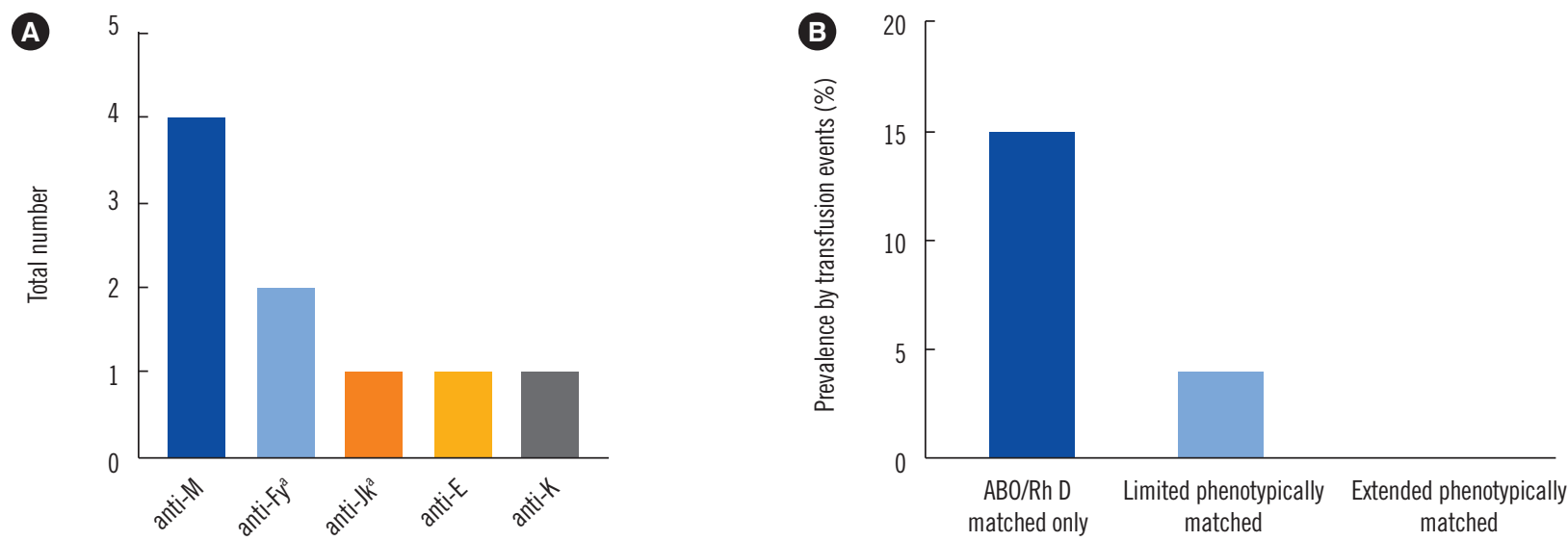

Fig. 1. RBC alloantibody distribution and prevalence of new antibody formation in pediatric patients with SCD in Puerto Rico. (A) Number and antigen specificity of the nine alloantibodies formed by eight alloimmunized pediatric SCD patients. (B) Alloantibody formation following RBC transfusion based on degree of serologic RBC phenotype matching. Abbreviations: see Table 1.

Table 1. RBC group antigen prevalence in 52 pediatric patients with SCD in Puerto Rico, as determined by serologic phenotype

\begin{tabular}{lcccccccccccccccccccc}
\hline RBC antigen & A & B & AB & O & D & C & E & C & E & M & N & S & S & $K$ & $k$ & $F^{a}$ & $F^{b}$ & $J^{b}$ & $J^{\mathrm{b}}$ \\
\hline Prevalence (\%) & 21 & 11 & 4 & 63 & 92 & 67 & 25 & 86 & 98 & 69 & 77 & 54 & 92 & 6 & 100 & 46 & 44 & 88 & 56 \\
\hline
\end{tabular}

Abbreviations: SCD, sickle cell disease; RBC, red blood cell. 


\section{Acknowledgements}

RBM thanks her fellowship mentors, Jeanne Hendrickson and Christopher Tormey, for their advice on this manuscript.

\section{Authors' Contributions}

All authors have accepted their responsibility for the entire content of this manuscript and approved its submission. RBM, CCP, and DMT designed and completed the research. RBM and CCP analyzed the raw data. Along with RBM and CCP, CND and RRR critically analyzed the findings. RBM wrote the first draft of the manuscript and all authors edited and approved the final submission.

\section{Conflicts of Interest}

None declared.

\section{Funding}

None declared.

\section{ORCID}

Raisa I. Balbuena-Merle https://orcid.org/0000-0002-79435597

Cruz M. Nazario-Delgado https://orcid.org/0000-0002-57534738
Rosa V. Rosario-Rosado https://orcid.org/0000-0002-11240400

Dalia Millán-Tapia https://orcid.org/0000-0002-3960-0113 Consuelo Climent-Peris https://orcid.org/0000-0002-0301-9917

\section{REFERENCES}

1. Kim HY, Cho EJ, Chun S, Kim KH, Cho D. Red blood cell alloimmunization in Korean patients with myelodysplastic syndrome and liver cirrhosis. Ann Lab Med 2019;39:218-22.

2. Chou ST, Jackson T, Vege S, Smith-Whitley K, Friedman DF, Westhoff $\mathrm{CM}$. High prevalence of red blood cell alloimmunization in sickle cell disease despite transfusion from Rh-matched minority donors. Blood 2013;122:1062-71.

3. Yazdanbakhsh K, Ware RE, Noizat-Pirenne F. Red blood cell alloimmunization in sickle cell disease: pathophysiology, risk factors, and transfusion management. Blood 2012;120:528-37.

4. Moreira Júnior G, Bordin JO, Kuroda A, Kerbauy J. Red blood cell alloimmunization in sickle cell disease: the influence of racial and antigenic pattern differences between donors and recipients in Brazil. Am J Hematol 1996;52:197-200.

5. Samarah F, Srour MA, Yaseen D, Dumaidi K. Frequency of red blood cell alloimmunization in patients with sickle cell disease in Palestine. Adv Hematol 2018;2018:5356245.

6. Dean L. Blood groups and red cell antigens. Bethesda: National Center for Biotechnology Information, 2005:32, 50, 57, 63, 69, 81.

7. Chou ST, Flanagan JM, Vege S, Luban NLC, Brown RC, Ware RE, et al. Whole-exome sequencing for $\mathrm{RH}$ genotyping and alloimmunization risk in children with sickle cell anemia. Blood Adv 2017;1:1414-22.

8. Chou ST, Evans P, Vege S, Coleman SL, Friedman DF, Keller M, et al. $\mathrm{RH}$ genotype matching for transfusion support in sickle cell disease. Blood 2018;132:1198-207. 